\title{
Transplantacja nerki jako metoda leczenia nerkozastępczego pacjenta z przewlekłą chorobą nerek
}

\author{
Kidney transplantation as a renal replacement therapy of patient with \\ chronic kidney disease
}

\author{
ALEKSANDRA WODERSKA-JASIŃSKA ${ }^{1}$, \\ MAŁGORZATA HERMANOWICZ2 ${ }^{2}$ ZBIGNIEW WŁODARCZYK ${ }^{3}$
}

1 Klinika Transplantologii i Chirurgii Ogólnej, Szpital Uniwersytecki nr 1 im. dr A. Jurasza w Bydgoszczy; Centrum Organizacyjno-Koordynacyjne ds. Transplantacji Poltransplant; Starszy asystent, Regionalny koordynator pobierania i przeszczepiania narządów, Koordynator pobierania i przeszczepiania nerek od żywych dawców

2 Centrum Organizacyjno-Koordynacyjne ds. Transplantacji Poltransplant w Warszawie; Główny specjalista, Centralny koordynator Centrum Organizacyjno-Koordynacyjnego ds. Transplantacji Poltransplant

3 Klinika Transplantologii i Chirurgii Ogólnej, Szpital Uniwersytecki nr 1 im. dr A. Jurasza w Bydgoszczy, Collegium Medicum im. L. Rydygiera w Bydgoszczy, Uniwersytet Mikołaja Kopernika w Toruniu

http://dx.doi.org/10.21784/IwP.2021.006

\section{Streszczenie}

Wstęp. Szacuje się, że przewlekła choroba nerek stanowi problem zdrowotny 500-600 milionów osób, z czego 4-5 milionów mieszkańców Polski, spośród których rocznie de novo 6500 wymaga leczenia nerkozastępczego. Transplantacja nerek jest uznaną metodą leczenia nerkozastępczego i najskuteczniejszą w porównaniu z alternatywnymi metodami leczenia przewlekłej choroby nerek - hemodializą i dializą otrzewnową.

Cel. Celem pracy jest przedstawienie aktualnego stanu wiedzy na temat wybranych zagadnień dotyczących przeszczepiania nerek jako metody leczenia nerkozastępczego w przewlekłej chorobie nerek. 
Przegląd. W pracy przedstawiono aktualny stan wiedzy na temat wybranych zagadnień dotyczących transplantacji nerek w Polsce od dawców zmarłych i żywych, w tym przeszczepień od żywych dawców niespokrewnionych w ramach Programu Wymiany Par.

Podsumowanie. Transplantacja nerek zapewnia chorym dłuższe przeżycie i lepszą jakość życia niż dializoterapia, dlatego jest metodą z wyboru w leczeniu schyłkowej niewydolności nerek.

Słowa kluczowe: przewlekła choroba nerek, leczenie nerkozastępcze, przeszczepienie nerki, Program Wymiany Par

\section{Abstract}

Introduction. It is estimated that 500-600 million people are affected by chronic kidney disease. In Poland, 6500 among 4-5 million patients with chronic kidney disease require renal replacement therapy de novo every year. Renal transplant is a well-established treatment of end-stage chronic kidney disease, and the most effective one in comparison to alternatives - hemodialysis and peritoneal dialysis.

Aim. Presenting the current condition of knowledge of issues is a purpose of the work to the subject chosen concerning transplanting kidneys as procedures in chronic nephropathy.

Review. In this review the author presents the current state of knowledge about selected aspects of kidney transplantation in Poland from deceased and living donors, including transplantations from nonrelated living donors (Kidney Paired Donation program).

Conclusions. Renal transplant allows to achieve both longer survival and better quality of life than dialysis and therefore is the treatment of choice in end-stage chronic kidney disease.

Key words: chronic kidney disease, renal replacement therapy, kidney transplant, Kidney Paired Donation program 


\section{Wstęp}

\section{Metody leczenia nerkozastępczego $\mathrm{w}$ przewlekłej chorobie nerek}

Przewlekła choroba nerek (PChN) zgodnie z międzynarodowymi zaleceniami Kidney Disease Improving Global Outcome (KDIGO 2012) to utrzymujące się powyżej 3 miesięcy nieprawidłowości budowy bądź czynności nerek, mające znaczenie dla zdrowia. Roczna zachorowalność na PChN wynosi ok. 150 osób na milion [1]. Wyniki badań epidemiologicznych dotyczące częstości występowania PChN w różnych częściach świata wykazały, że oscyluje w granicach 9-15\% badanych populacji. Szacuje się więc, że średnio 10-11\% populacji świata znajduje się w jednym ze stadiów zaawansowania choroby, co oznacza że przewlekła choroba nerek dotyczy 500-600 milionów osób, z czego 4-5 milionów mieszkańców Polski [2]. Badanie PolNef przeprowadzone w Europie Środkowo-Wschodniej, w tym w Polsce, wykazało obecność PChN u 11.9-18\% populacji, w zależności od zastosowanych kryteriów $[1,2]$. Przewlekła choroba nerek jest drugą, po nadciśnieniu tętniczym, najczęściej występującą przewlekłą chorobą w Polsce, jednak około 90\% chorych nie jest świadomych obecności choroby. Pomimo, że we wczesnej fazie choroba jest łatwo wykrywalna i stosunkowo prosta do leczenia, to $\mathrm{w}$ zaawansowanej fazie ma często trudny do przewidzenia przebieg i rozpoznana zbyt późno skutkuje utratą czynności nerek i koniecznością wdrożenia leczenia nerkozastępczego - dializami lub przeszczepieniem nerki - w Polsce co roku de novo u co najmniej 6500 osób (około 170 osób na milion mieszkańców). Na koniec 2018 roku w Polsce leczenie nerkozastępcze stosowano u ponad 32000 chorych, zaś nerki przeszczepiono tego roku 927 pacjentom [3, 4, 5]. Przeszczepienie nerki (KTx) przywraca prawidłową homeostazę wewnątrzustrojową i czynność wewnątrzwydzielniczą. Jest uznaną metodą leczenia nerkozastępczego i najskuteczniejszą w porównaniu z alternatywnymi metodami leczenia przewlekłej choroby nerek - hemodializą i dializą otrzewnową. Zapewnia chorym dłuższe przeżycie i lepszą jakość życia niż dializoterapia, dlatego jest metodą z wyboru w leczeniu schyłkowej niewydolności nerek. Każdy chory z nieodwracalną niewydolnością ne- 
rek powinien być rozważany jako kandydat do przeszczepienia nerki i informowany o możliwości zastosowania tej formy leczenia $[1,5]$.

Zgłaszani do zabiegu przeszczepienia nerki powinni być pacjenci, którzy wyrazili zgodę na kwalifikację do transplantacji i u których na podstawie wstępnej oceny wykluczono obecność przeciwwskazań do wdrożenia tej metody leczenia nerkozastępczego. Szacuje się, że powinni oni stanowić około $25-30 \%$ chorych dializowanych $[5,6]$.

\section{Cel}

Celem pracy jest przedstawienie aktualnego stanu wiedzy na temat wybranych zagadnień dotyczących przeszczepiania nerek jako metody leczenia nerkozastępczego w przewlekłej chorobie nerek.

\section{Przegląd}

\section{Transplantacja nerki jako metoda leczenia}

Pierwsze skuteczne przeszczepienie nerki w Polsce wykonano 26 stycznia 1966 roku. Dotychczas (1966-2019) w Polsce przeszczepiono 25409 nerek, w tym 24496 od dawców zmarłych i 913 od dawców żywych. W 2019 r. nerki przeczepiono 959 biorcom, w tym 907 od dawców zmarłych [7].W międzynarodowych rejestrach gromadzących dane dotyczące pobierania i przeszczepienia narządów, Polska w 2019 roku została odnotowana na 29 miejscu spośród 73 krajów pod względem liczby przeszczepień nerek od dawców zmarłych w przeliczeniu na milion mieszkańców (24,12 pmp). Najwięcej nerek od dawców zmarłych w 2019 roku przeszczepiono w Hiszpanii - 66,55 pmp, zaś najmniej w Maroko - 0,1 pmp [8].

Zgodnie z obowiązującymi w Polsce regulacjami prawnymi warunkiem otrzymania przeszczepu jest umieszczenie chorego na Krajowej Liście Oczekujących (KLO), którą prowadzi Centrum Organizacyjno-Koordynacyjne ds. Transplantacji Poltransplant [9].

W 2019 roku na KLO do przeszczepienia nerki było zarejestrowanych 2747 chorych, w tym 39 pacjentów pediatrycznych, zaś aktywnie oczekiwało 1165 chorych. 73\% (854) chorych oczekiwało na pierwsze 
przeszczepienie nerki, co piąta osoba (245) na drugie, 60 pacjentów na trzecie, zaś 6 na czwarte przeszczepienie. Średni wiek potencjalnych biorców wyniósł 49 lat [10].

\section{Wskazania i przeciwwskazania do przeszczepienia nerki}

Przygotowania do leczenia nerkozastępczego, w tym kwalifikację do przeszczepienia nerki należy rozpocząć u chorych z przewlekłą chorobą nerek w stadium 5., gdy wartość przesączania kłębuszkowego (eGFR, estimated glomerular filtration rate) wynosi poniżej $15 \mathrm{ml} /$ $\mathrm{min} / 1,73 \mathrm{~m}^{2}$, zaś u chorych z cukrzycą poniżej $20 \mathrm{ml} / \mathrm{min} / 1,73 \mathrm{~m}^{2}$. U chorych z cukrzycą typu 1 należy rozważyć jednoczasowe przeszczepienie nerki i trzustki. W każdym przypadku chorzy wymagający leczenia nerkozastępczego powinni być rozważani jako potencjalni kandydaci do przeszczepiania nerki ( $w$ tym od dawcy żywego). Korzystniejsze, ponieważ wydłużające przeżycie zarówno biorcy, jak i graftu jest przeszczepienie nerki jeszcze przed włączeniem chorego w program dializ (tzw. przeszczepienie wyprzedzające, pre-emptive) [1, 5]. W 2019 roku na KLO zgłoszono de novo 100 pacjentów przed rozpoczęciem dializ, a 42 chorych przeszczepiono w trybie wyprzedzającym [10]. Średni czas oczekiwania na przeszczepienie od rozpoczęcia dializ do przeszczepienia dla chorych zgłoszonych do pierwszego przeszczepienia w 2019 roku wynosił 908 dni, zaś od zakwalifikowania na KLO do przeszczepienia - 366 dni. Chorzy zgłoszeni do kolejnej transplantacji od zakwalifikowania oczekiwali na transplantację średnio $621 \mathrm{dni}$, zaś pacjenci wysokoimmunizowani 762 dni. Chorzy zgłoszeni do przeszczepień pilnych, którzy zgodnie z kryteriami alokacji należą do grupy biorców z pierwszeństwem w wyborze do przeszczepienia niezależnie od liczby uzyskanych punktów, na pierwsze przeszczepienie oczekiwali średnio 49 dni, zaś na drugie - 273 dni. W 2019 roku oczekując na przeszczepienie nerki zmarło 75 chorych [10].

Warunkiem uzyskania pomyślnego wyniku transplantacji jest właściwa kwalifikacja chorego do zabiegu chirurgicznego i leczenia immunosupresyjnego, w tym ocena stanu zdrowia i obecności ewentu- 
alnych przeciwwskazań bezwzględnych i względnych (czasowych) [5]. Do przeciwwskazań bezwzględnych należą: uogólniona choroba nowotworowa, niedające się opanować zakażenia; zapalenie kości i szpiku kostnego, AIDS, agresywne wirusowe zapalenie wątroby; znaczne uszkodzenie innych narządów i układów obciążające rokowanie - wówczas w wybranych przypadkach można rozważyć przeszczep wielonarządowy (nerka + wątroba, nerka + serce, nerka + płuca + serce); brak współpracy pacjenta - choroby psychiczne, narkomania, alkoholizm; bardzo podeszły wiek, spodziewany czas przeżycia <2 lat oraz miażdżyca uogólniona z zaawansowanymi zmianami narządowymi [11].

\section{Dobór dawcy i biorcy}

Przeszczepiane nerki pobierane są od dawców żywych lub zmarłych. Zasadniczym warunkiem jest zgodność głównych grup krwi dawcy i biorcy oraz ujemny wynik próby krzyżowej (cross-match) pomiędzy limfocytami dawcy i surowicą biorcy, który wyklucza obecność u biorcy przeciwciał limfocytotoksycznych skierowanych przeciwko antygenom dawcy [11].

Zdecydowana większość chorych w Polsce otrzymuje nerkę pobraną od dawcy zmarłego. Niewielki odsetek nerek pobieranych jest od dawców żywych (5,4\% w 2019 r.). Pierwszą nerkę od dawcy żywego pobrano i przeszczepiono w Polsce w 1966 roku, zaś do końca 2019 roku przeszczepiono ich łącznie 913. W 2015 r. przeszczepiono 60 nerek pobranych od dawców żywych - dotychczas najwięcej w skali roku, osiągając wskaźnik 1,55 na milion mieszkańców (pmp) [12]. Najwyższy wskaźnik w 2019 r. odnotowano w Turcji - 36,64 pmp. [8].

Ze względu na znaczną dysproporcję pomiędzy liczbą chorych z przewlekłą chorobą nerek oczekujących na przeszczepienie a dostępnością narządów do transplantacji ustanowiono Narodowy Programu Rozwoju Medycyny Transplantacyjnej Ministerstwa Zdrowia na lata 20112020. Jednym z celów Programu jest zwiększenie liczby transplantacji nerek od dawców żywych. Oczekuje się, że po jego zakończeniu liczba biorców nerek od dawców żywych zwiększy się co najmniej pię- 
ciokrotnie w stosunku do liczby przeszczepień w 2009 r., kiedy to nerki od dawców żywych przeszczepiono 23 pacjentom (0,6 pmp), czyli wyniesie co najmniej 115 [13]. Do końca listopada 2020 roku nerki od dawców żywych zostały przeszczepione 31 biorcom. Mając na uwadze stan pandemii w 2020 roku i wynikające z tego następstwa dla programu transplantacji nerek, dla porównania do końca 2019 roku pobrano 52 nerki od dawców żywych. Pomimo, że nominalnie nie osiągnięto założonego celu, to liczba przeszczepień uległa istotnemu zwiększeniu już w kolejnym roku po wprowadzeniu Programu i od dekady wynosi średnio 51 przeszczepień rocznie. Ponadto w 2014 roku w Polsce wdrożono Program Wymiany Par, czyli program przeszczepień krzyżowych i łańcuchowych od żywych dawców niespokrewnionych.

\section{Program Wymiany Par}

Program Wymiany Par (KPD, Kidney Paired Donation) jest metodą pozwalającą na poszerzenie możliwości przeszczepień od dawców żywych dla biorców, u których istnieją przeciwwskazania immunologiczne do przeszczepienia bezpośredniego z powodu niezgodności grup krwi lub dodatniego wyniku próby krzyżowej. Program zakłada powiązanie ze sobą co najmniej dwóch par dawca-biorca i pobranie nerki od dawcy żywego w celu przeszczepienia jej biorcy z innej pary, w zamian za przeszczepienie biorcy nerki od dawcy z pary, która jest w analogicznej sytuacji $[14,15]$. Przeszczepianie nerek od żywych dawców niespokrewnionych w ramach wymiany par (przeszczepień krzyżowych i łańcuchowych) jest uznaną metodą stosowaną w Europie i na świecie. Pierwsze przeszczepienie krzyżowe przeprowadzono w 1991 r. w Korei Południowej, choć idea powstała w 1989 r. w Stanach Zjednoczonych. W Europie pierwsze przeszczepienie w ramach programu wymiany par odbyło się w 1999 roku w Szwajcarii, następnie w Rumunii (2001 r.) i Holandii (2004 r.) [16]. W październiku 2014 roku Polska dołączyła do grupy krajów realizujących program. Po czterech miesiącach od wdrożenia programu w Warszawie przeprowadzono pierwsze przeszczepienie krzyżowe i łańcuchowe. Kolejne przeszczepienie krzyżowe prze- 
prowadzono rok później w Bydgoszczy. Dotychczas w Polsce wykonano sześć przeszczepień krzyżowych jednoośrodkowych lub we współpracy pomiędzy dwoma ośrodkami transplantacyjnymi (Warszawa, 2015; Bydgoszcz 2016; Warszawa-Szczecin, 2017; Bydgoszcz-Wrocław, 2017; Wrocław, 2019; Wrocław-Szczecin, 2020) i jedno łańcuchowe (Warszawa, 2015).

Program Wymiany Par realizowany jest przez Centrum Organizacyjno-Koordynacyjne ds. Transplantacji Poltransplant z siedzibą w Warszawie, który centralnie gromadzi zgłoszenia par kandydat na dawcę potencjalny biorca i koordynuje proces ich doboru, także pod względem immunologicznym, a następnie sprawuje nadzór nad przebiegiem procedur medycznych i formalno-prawnych w ośrodkach transplantacyjnych. Dotychczas (2014-2020) do Poltransplantu zgłoszono łącznie 98 par dawca-biorca. Ponieważ kwalifikacja biorcy do przeszczepienia od dawcy żywego, w tym w ramach Programu Wymiany Par, nie dyskwalifikuje chorego z możliwości otrzymania nerki od dawcy zmarłego, połowie pacjentów w czasie oczekiwania przeszczepiono nerkę pobraną ze zwłok. Drugą najczęstszą (14\%) przyczynę dyskwalifikacji par z programu stanowiła obecność przeciwwskazań medycznych u kandydatów na dawców, m.in. choroby nowotworowe, schorzenia genetyczne, otyłość patologiczna, nadciśnienie tętnicze z powikłaniami narządowymi, cukrzyca, anomalie naczyniowe nerek, GFR $<60 \mathrm{ml} / \mathrm{min}$, krwiomocz, białkomocz i miażdżyca. 10\% par zdyskwalifikowano z powodu przeszczepienia biorców od dawców żywych bezpośrednio - w zakresie pary, gdy po zgłoszeniu do programu powtórzono próbę krzyżową i/lub zakwalifikowano innego kandydata na dawcę. Ponadto, dwie pary zdyskwalifikowano z powodu stanu biorców, m.in. ciąży; dwie z powodu zgonów biorców (niewydolność krążeniowa) i w jednym przypadku odstąpiono od dalszej procedury decyzją dawcy o rezygnacji z programu. W połowie grudnia 2020 roku w rejestrze Poltransplantu znajdowały się 24 aktywne pary: $2 / 3$ zostało zgłoszonych do programu z powodu dodatniej próby krzyżowej (cross-match), zaś $1 / 3$ z powodu niezgodnych grup krwi dawcy i biorcy. Spośród 24 potencjalnych biorców 
10 oczekiwało na pierwszą transplantację, 8 na drugie przeszczepienie, 5 na trzecie, a jeden pacjent na czwarte [17].

\section{Wyniki leczenia nerkozastępczego}

Prognozowany czas przeżycia biorcy nerki wynosi 20 lat i jest dwukrotnie dłuższy od szacowanej długości życia chorego dializowanego, dlatego przeszczepienie nerki stanowi metodę z wyboru w leczeniu schyłkowej niewydolności nerek [5, 11]. W Polsce roczna przeżywalność biorców nerki wynosi 95\%, zaś przeszczepionych nerek - 90\%. Wyniki przeszczepienia wyprzedzającego (przez włączeniem chorego w program dializ) są lepsze niż transplantacji nerki przeprowadzonej już w okresie dializoterapii. Także wyniki przeszczepiania nerek od dawców żywych są lepsze w porównaniu do graftów od dawców zmarłych [11]. Analiza wyników przeszczepienia nerek w Polsce na podstawie transplantacji wykonanych w latach 1996-2007 wykazała, że po 15 latach od przeszczepienia od dawcy żywego żyje 79\% biorców i funkcjonuje $57 \%$ przeszczepionych nerek, zaś po przeszczepieniu od dawcy zmarłego żyje $61 \%$ biorców i funkcjonuje 45\% graftów [18].

Do utraty przeszczepów dochodzi najczęściej z powodu przewlekłego odrzucania, IF/TA (Renal Interstitial Fibrosis / Tubular Atrophy) nawrotu choroby podstawowej i glomerulopatii de novo. Główne przyczyny zgonów biorców stanowią choroby układu serowo-naczyniowego (40\%), zakażenia (17\%) i nowotwory (12\%) [11].

\section{Wnioski}

Transplantacja nerek jest najskuteczniejszą metodą leczenia nerkozastępczego, $\mathrm{w}$ porównaniu $\mathrm{z}$ innymi metodami terapii przewlekłej choroby nerek - hemodializą i dializą otrzewnową. Przeszczepienie nerki u właściwie zakwalifikowanych chorych umożliwia im dłuższe przeżycie i lepszą jakość życia niż dializoterapia, dlatego jest metodą z wyboru w leczeniu chorych z PChN. Zdecydowana większość przeszczepianych w Polsce nerek pobierana jest od dawców zmarłych. Przeszczepianie nerek od dawców żywych (spokrewnionych i niespo- 
krewnionych, w tym w ramach programu wymiany par), oprócz lepszych wyników przeżycia biorców i przeszczepów w porównaniu do transplantacji od dawców zmarłych, umożliwia skrócenie czasu oczekiwania na przeszczepienie - średnio rocznego w przypadku dawcy zmarłego i wykonanie zabiegu w trybie planowym.

\section{Bibliografia/Bibliography:}

1. Myśliwiec M. Przewlekła choroba nerek. [W:] Interna Szczeklika 2018, 10 wydanie, Medycyna Praktyczna, Kraków 2018:1541-1551.

2. Rutkowski B. Przewlekła choroba nerek - dziesięć lat w teorii i praktyce, Forum Nefrologiczne 2013, tom 6, nr 1:63-70.

3. Gellert R. (Red.) Opieka koordynowana nad pacjentem z przewlekłą chorobą nerek. Nefron Sekcja Nefrologiczna Izby Gospodarczej Medycyna Polska, Grudzień 2018.

4. Antoszkiewicz K., Czerwiński J., Pobieranie i przeszczepianie narządów w Polsce w 2018 r., Poltransplant Biuletyn Informacyjny, 2019;2:5-23.

5. Nieszporek T., Więcek A. Kwalifikacja chorych do przeszczepienia nerki. [W:] Durlik M., Cierpka L. (Red.), Transplantologia kliniczna, Przeszczepy narządowe. Termedia, Poznań 2015:17-32.

6. Durlik M., Klinger M. Chory dializowany jako biorca przeszczepu, Forum Nefrologiczne 2010;3,3:201-211.

7. Antoszkiewicz K., Czerwiński J. Pobieranie i przeszczepianie narządów w Polsce w 2019 r., Poltransplant Biuletyn Informacyjny 2020;1(29):5-19.

8. International Registry in Organ Donation and Transplantation, June 2020, www.irodat.org, 11.12.2020, from https://www.irodat.org/img/ database/pdf/Newsletter\%20June\%202020\%200ct.pdf.

9. Obwieszczenie Marszałka Sejmu Rzeczypospolitej Polskiej z dnia 4 listopada 2020 r. w sprawie ogłoszenia jednolitego tekstu ustawy o pobieraniu, przechowywaniu i przeszczepianiu komórek, tkanek i narządów, Dz. U. z 2 grudnia 2020 r. Nr 2134. 
10. Lewandowska D., Borczon S., Przygoda J., Hermanowicz M., Podobińska I., Michalska K., Mańkowski M. Krajowa lista osób oczekujących na przeszczepienie (KLO). Poltransplant Biuletyn Informacyjny 2020;1(29):23-37.

11. Rutkowski B., Wańkowicz Z., Durlik M. Leczenie nerkozastępcze. [w:] Interna Szczeklika 2018 Medycyna Praktyczna, Kraków 2018;10:1650-1659.

12. Antoszkiewicz K., Mańkowski M., Czerwiński J., Pobieranie i przeszczepianie narządów w Polsce w 2015 r., Poltransplant Biuletyn Informacyjny 1(24), maj 2016:14-32.

13. Uchwała Nr 164/2010 Rady Ministrów z dnia 12 października 2010 r. w sprawie ustanowienia programu wieloletniego na lata 2011-2020 pod nazwą „Narodowy Program Rozwoju Medycyny Transplantacyjnej”.

14. Lewandowska D., Czerwiński J. Zasady i warunki pobierania i krzyżowego przeszczepiania nerek od żywych dawców (wymiany nerek w parach). Poltransplant Biuletyn Informacyjny 1(23) maj 2015:23-24.

15. Hermanowicz M., Borczon S., Czerwiński J., Lewandowska D., Przygoda J., Podobińska I., Malanowski P. System jakości dawstwa nerek do przeszczepienia od żywych dawców. Poltransplant Biuletyn Informacyjny 2020; 1(29):56-59.

16. Ellison B. A Systematic Review of Kidney Paired Donation: Applying Lessons From Historic and Contemporary Case Studies to Improve the US Model (2014). Wharton Research Scholars Journal. Paper 2014:107.

17. Hermanowicz M. Krajowa Lista Oczekujących Centrum Organizacyjno-Koordynacyjne ds. Transplantacji Poltransplant, dane niepublikowane [stan na 11 grudnia 2020].

18. Malanowski P. Polska medycyna transplantacyjna w liczbach (grafy). Poltransplant Biuletyn Informacyjny Nr 1(26)2018:103-114. 